
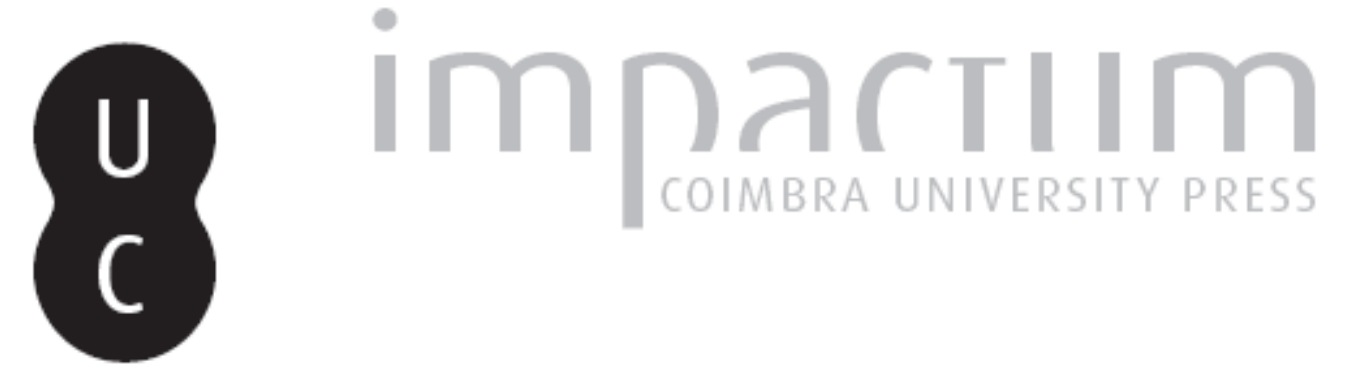

\title{
O sentimento (aísthesis) de igualdade e a igualação conceitual
}

\author{
Autor(es): $\quad$ Mees, Leonardo
}

Publicado por: Universidade Católica de Petrópolis

URL persistente:

URI:http://hdl.handle.net/10316.2/33909

DOI:

DOI:http://dx.doi.org/10.14195/2175-0947_1-1_9

Accessed : $\quad$ 26-Apr-2023 11:52:23

A navegação consulta e descarregamento dos títulos inseridos nas Bibliotecas Digitais UC Digitalis, UC Pombalina e UC Impactum, pressupõem a aceitação plena e sem reservas dos Termos e Condições de Uso destas Bibliotecas Digitais, disponíveis em https://digitalis.uc.pt/pt-pt/termos.

Conforme exposto nos referidos Termos e Condições de Uso, o descarregamento de títulos de acesso restrito requer uma licença válida de autorização devendo o utilizador aceder ao(s) documento(s) a partir de um endereço de IP da instituição detentora da supramencionada licença.

Ao utilizador é apenas permitido o descarregamento para uso pessoal, pelo que o emprego do(s) título(s) descarregado(s) para outro fim, designadamente comercial, carece de autorização do respetivo autor ou editor da obra.

Na medida em que todas as obras da UC Digitalis se encontram protegidas pelo Código do Direito de Autor e Direitos Conexos e demais legislação aplicável, toda a cópia, parcial ou total, deste documento, nos casos em que é legalmente admitida, deverá conter ou fazer-se acompanhar por este aviso.

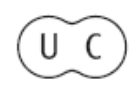



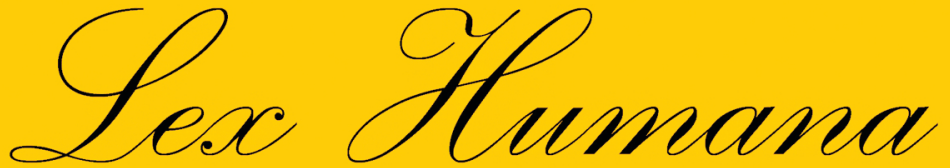

Revista do Programa de Pós-Graduação em Direito da UCP

ISSN(e) 2175-0947

Universidade Católica de Petrópolis Rua Benjamin Constant, 213 - Petrópolis - Centro CEP 25610-130

Tel: (24) 2244-4000 E-mail: lexhumana@ucp.br 


\section{O SENTIMENTO (AÍSTHESIS) DE IGUALDADE E A IGUALAÇÃO CONCEITUAL}

Leonardo Mees

Quando o todo houver sido afinal dividido igualmente, então as partes litigantes dirão que têm aquilo que lhes pertence - isto é, quando elas houverem obtido o que é igual (tò íson). Aristóteles

\section{Introdução}

$\mathrm{O}$ art. $5^{\circ}$, caput, de nossa Constituição Federal de 1988 enuncia a igualdade de todos perante a lei, "sem distinção de qualquer natureza". Ressoa aqui o acorde fundamental de introdução no capítulo dos "direitos e deveres individuais e coletivos" e, como tal, evoca a tônica de resolução harmônica dos diversos encadeamentos e até das possíveis dissonâncias que compõe a fuga legal deste capítulo inaugural e indispensável em uma carta magna de declaração de direitos. No entanto, a tradição do regime liberal, rica na consagração de privilégios e distinções, não tem dado tanta atenção à igualdade. "Por isto, - diz José Afonso da Silva - é que a burguesia, cônscia de seu privilégio de classe, jamais postulou um regime de igualdade tanto quanto reivindicara o de liberdade". " Além da "igualdade" ser entoada aqui em sentido jurídico-formal, como consideração abstrata sobre o plano isonômico da lei, há ainda uma vibração programática de "igualação material" dos desiguais, por atribuição de direitos sociais indispensáveis. A distinção entre "isonomia material e formal" tornou-se a ferramenta usual de superação do plano da interpretação meramente literal do caput do art. $5^{\circ}$. Ao passo que o propósito de aproximação das divergências entre estes dois tipos de isonomia tem sido a orientação prática dos tribunais nos casos concretos de discriminação e de desigualação injusta dos iguais perante a lei ${ }^{2}$.

1 SILVA, José Afonso da. Curso de Direito Constitucional positivo. São Paulo: Malheiros Editores, 2002, p. 210.

2 Cf. O "princípio da isonomia" foi inclusive recentemente o "fundamento" 
Apesar de sabermos que a igualdade proposta pela Constituição "se configura como uma eficácia transcendente", abone as desigualdades incompatíveis com sua proposta programática, também sabemos que não é legítima a afirmação de que, desde a entrada em vigor desta garantia constitucional de igualdade, as formas injustas de desigualação perante a lei e o direito tenham sido abolidas, sem se falar ainda das radicais desigualdades econômico-sociais. Todas desigualdades na aplicação do Direito revoltam! Por vezes, infelizmente até alguns membros do Judiciário são coniventes com a existência destas desigualdades, ao concederem liminares a empresários caçadores de níqueis e a prenderem pobres mendicantes da "moedinha do tio".

Mas aqui não vamos tratar das muitas razões históricas e sociológicas que corroboram com a manutenção deste estado de desigualdades materiais em nosso país. Também não vamos comentar os diversos dispositivos legais, quiçá bem escritos e altissonantes, que deveriam por si mesmos ser suficiente para "transformar a sociedade". Não vamos convocar os "companheiros" a uma luta juridicamente municiada contra as desigualdades e os privilégios processuais dos mais ricos nem vamos propor "reformas" nos diversos sistemas jurídicos existentes. Não! Mudemos de direção! Nossa proposta é mais modesta, limitada, finita: acessível a qualquer um que queira, segundo Kant, "sair de sua menoridade", que queira "servir-se de si mesmo" e pensar (sapere aude!) ${ }^{4}$. Pensar com auto-nomia significa assumir seu próprio não-saber, investigar com sua própria ignorância (docta ignorantia), deixando se conduzir pelos vestígios de uma questão relevante para si mesmo... Esta mudança de direção do pensamento "transcende o plano meramente normativo, para questionar o critério de justiça adotado nas normas jurídicas" fundamento do direito e da justiça, a Filosofia do Direito não se delimita

alegado pelo pedido do Habeas Corpus, feito ao Ministro Gilmar Mendes, do Supremo Tribunal Federal, pelos presos na "Operação Navalha" da Polícia Federal, contra o pedido de prisão preventiva, expedido pela Ministra Eliana Calmon, do Superior Tribunal de Justiça. Vide Méd. Caut. em Habeas Corpus 91.524-8 Bahia. 3 Vide MORAES, Alexandre de. Direito Constitucional. São Paulo: Atlas S.A., 2003, p. 66.

4 Cf. KANT, Immanuel. Resposta à pergunta: Que é "Esclarecimento" (Aufklärung). In: Textos Seletos, Petrópolis: Vozes: 2005, p. 63.

5 NADER, Paulo. Introdução ao estudo do Direito. Rio de Janeiro:

Forense, 2001, p. 11. 
apenas com a questão pelo "quid jus", uma vez que a investigação supera a objetividade da res de cada quid e se lança no empenho de assinalar o quis do projeto genético de todo mundo de sujeitos e objetos ${ }^{6}$. Isto porque o pensamento é sempre pobre em reificação, não consegue dizer que o querer (quaere) da sua questão (quaestio) seja uma "coisa" (res) ao lado de outras tantas coisas, já dadas e conhecidas. Pensar na Filosofia do Direito significa perceber-se implicado no próprio questionamento, acompanhar e investigar o querer da própria questão, de modo a deixar renascer e a recriar o próprio conceito pesquisado. Por isto, todo pensamento jusfilosófico é genético, i.é, compartilha da constituição dos conceitos de direito e justiça.

Vamos então tentar pensar a constituição genética da "igualdade" na convivência humana. Por que? Porque normalmente entendemos a igualdade apenas segundo duas orientações: a igualdade formal e a igualdade material. Ou as coisas são "realmente" iguais materialmente, i.é, têm idênticas constituições físicas e atômicas... Ou as coisas são pretensamente "representadas" como iguais segundo uma forma, i.é, segundo uma categoria ou classificação abstrata. Mas, as ciências físicas modernas destroem o nosso conceito de igualdade material, nos ensinam o que já diz uma canção: "tudo na vida passa... nada é igual a nada não" (The Fevers - Elas por elas). Na natureza não há igualdade e os fenômenos físicos precisam ser subsumidos como iguais para serem estudados e controlados ${ }^{7}$. Só resta então acreditar que a "igualdade" decorre de um processo de representação da realidade, diga-se: de um processo essencialmente humano, pois, somente sob a ótica finita da perspectiva humana as coisas podem ser consideradas como "materialmente iguais".

Então nos perguntamos: como podemos "assegurar" que um juiz possa julgar com "igualdade" aquilo que cientificamente é desigual? E, em termos de "segurança jurídica", como garantir que a sentença do juiz

6 M. Garcia Morente nos ensina que o questionamento radical não consegue definir com propriedade o ser em questão, apenas assinala o "quem" de sua autenticidade. 'Esta variação de 'quem' em vez de 'que' nos faz ver que esta segunda pergunta tende não a definar, mas a assinalar o ser para podê-lo intuir diretamente e sem definição nenhuma". MORENTE, M. Garcia. Fundamentos de Filosofia. São Paulo: Mestre Jou, 1967, p. 59.

7 Cf. HEISENBERG, Werner. Más allá de la fisica. Madrid: Biblioteca de Autores Cristianos, 1974, p. 134: "Pero como prácticamente no se da jamás en los fenómenos la igualdad completa, establecemos la igualdad específica a través del proceso de abstracción"... 
tomou partido, em seu processo de julgamento, no princípio da isonomia? Naturalmente que aqui não estamos falando apenas das garantias objetivas e legais de igualdade, que podem ser argüidas, em tempo oportuno dentro do processo e por meio de recursos, pelas partes lesadas, pois "formalmente": perante a lei todos somos iguais. Em questão está o tratamento igualitário que depende subjetivamente do próprio juiz, ou seja, queremos pensar sobre o "sentido e a sensibilidade" que fundamenta o juízo isonômico. O princípio da "igualdade" no Direito é um mandamento de neutralidade subjetiva? Será que o juiz somente é "justo" quando se mantém insensível, distante, alheio, burocrata, no sentido pejorativo? Será que a sensibilidade do juiz só passa a ser influenciada pelo processo quando para ele é "um peso e um enfado ter de julgar" coisas tão vis e desprezíveis?! O magistrado aposentado e doutor em Direito, João Batista Herkenhoff, tem uma outra visão da sensibilidade do juiz:

Vejo o juiz como um poeta, alguém que morre de dores que não são suas, alguém que vive o drama dos processos, alguém capaz de descer às pessoas que julga, alguém que capta os sentimentos as aspirações da comunidade, alguém que incorpora na sua alma e na sua vida a fome de justiça do povo a que serve. ${ }^{8}$

A analogia estabelecida por Herkenhoff entre o juiz e o poeta não nos parece despropositada, pois destaca aquilo sobre o que pretendemos tratar aqui: "a constituição humana do sentimento de da igualdade". Compreendemos existencialmente o que seja "igualdade", quando a vivenciamos numa experiência de comunidade, mas ao tentar conceituála acabamos abandonando o solo deste fenômeno. E assim, nos ocorre o mesmo que a Santo Agostinho, com o seu conceito de tempo: "se ninguém me perguntar, eu sei; se quiser explicar a quem me fizer a pergunta, já não sei"'.

A "igualdade" depende exclusivamente dos sentidos humanos, tratase de uma consideração tipicamente baseada na sensibilidade humana. Assim, 8

HERHENHOFF, João Batista. A formação dos operadores jurídicos no Brasil. In: ARRUDA SAMPAIO, Plínio et alii (org.). Ética, Justiça e Direito. Reflexões sobre a reforma do judiciário. Petrópolis: Vozes, 1997, p. 178.

SANTO AGOSTINHO. Confissões. Petrópolis: Vozes, 1988, p. 278. 
para nos lembrarmos da força de significação que tem a "igualdade" dentro da convivência humana e sobre a qual se erige o princípio de isonomia jurídica, percorreremos duas etapas reflexivas: 1. Nietzsche lançará por terra nossa ingênua crença na "realidade" da palavra igualdade, seremos reconduzidos ao inter-esse fundante da igualação comunitária: a relação afetiva do homem com o mundo; 2. Com Aristóteles veremos que nossa sensibilidade sustenta nossa comunicação e que sente o mundo de forma diferente dos demais animais. A linguagem simboliza o sentimento comum de justiça, na origem de toda igualação feita pela linguagem habita um sentimento de justiça.

Seguindo este percurso pretendemos chegar à simples conclusão: a igualdade não consiste num mandamento heteronômico, imposto pela lei sobre nossa subjetividade, mas no "sentimento (aísthesis) fundamental de nossa humanização". No entanto, este sentimento de igualdade requer sempre uma experiência individual, uma participação concreta na comunidade. Nosso objetivo será somente enfocar a relevância da retomada do sentimento originário de criação das igualdades na convivência social, ou seja, somente a experiência e o sentimento concreto de gênese de uma estrutura social pode reconhecer e justificar a igualdade. Sabe o "que" ou "quem" é a igualdade aquele sente e experimenta numa comunidade o que significa ser homem! ${ }^{10}$

\section{A igualação dos conceitos}

Quando Nietzsche vira a terra batida dos conceitos filosóficos, com o seu arado crítico (Pflugschar), ele procura "iluminar a história da gênese desse mundo de representação"11. Mas, um dos grandes defeitos dos filósofos e dos eruditos em geral, segundo Nietzsche, consiste em não compreender que o mundo, tal como vemos e representamos com nossos conceitos, não existe

10

A questão da "igualdade" é multifacetada. Aqui somente abordamos o sentido filosófico da igualdade instauradora da comunidade humana, vale dizer, a igualdade genética do ser humano. Ficam como dica de leitura das várias outras faces do problema os livros de DWORKIN, Ronald. A virtude soberana: a teoria e a prática da igualdade. São Paulo: Martins Fontes, 2005 e BOBBIO, N. , MATTEUCCI, n. E PASQUINO G. (orgs.). Dicionário de política. Vol. I, Brasília: Ed. UNB, 1998, p. 597-605.

11 NIETZSCHE, F. Humano, Demasiado Humano. Trad. Paulo César de Souza, São Paulo: Companhia das Letras, 2004, p. 27 (§ 16): “O que agora chamamos de mundo é o resultado de muitos erros e fantasias que surgiram gradualmente na evolução total dos seres orgânicos..." 
independente de nossa relação com ele. O mundo não caiu do céu, como uma estrela cadente. Foram as crenças, estruturadas pela relação afetiva do homem com seu entorno, que interpretaram e constituíram as "verdades" dos conceitos. Nenhuma crença em verdades lógicas se estabeleceu fora de um processo relacional do homem com o seu mundo em constituição: "Mas tudo veio a ser, não existem fatos eternos: assim como não existem verdades absolutas"12. Escrever a "história da gênese deste mundo" não significa procurar atrás dos fenômenos a "coisa em si” ou a verdade das aparências. A descrição genética do conhecimento lógico e dos conceitos não pode servirse de conceitos já constituídos. Precisa "conceituar" novamente, ou seja, interpretar e apropriar-se da própria gênese da conceituação sensível.

Entre as gêneses descritas no terceiro livro de "A gaia ciência", encontramos um ensaio de Nietzsche sobre a "origem do lógico" (§ 111). Nietzsche propõe remeter a origem dos conceitos lógicos a um processo de reconhecimento da "igualdade, no tocante à alimentação ou aos animais". Trata-se de um processo de determinação das "probabilidades de sobrevivência". Numa determinada situação limite o homem se vê às voltas com as desigualdades do desconhecido e com as semelhanças do já conhecido.

Quem, por exemplo, não soubesse distinguir com bastante freqüência o "igual", no tocante à alimentação ou aos animais que lhe eram hostis, isto é, quem subsumisse muito lentamente, fosse demasiado cauteloso na subsunção, tinha menos probabilidade de sobrevivência do que aquele que logo descobrisse igualdade em tudo o que era semelhante. Mas a tendência predominante de tratar o que é semelhante como igual - uma tendência ilógica, pois nada é realmente igual - foi o que criou todo fundamento para a lógica. ${ }^{13}$

Nesta situação, quem não reconhece o semelhante como igual sucumbe, quem demora a reagir diante dos perigos fracassa... A igualdade é um instrumento prático que amplia as probabilidades de sobrevivência. Para 12 Idem, p. 16.

13 NIETZSCHE, F. A gaia Ciência. Trad. Paulo César de Souza, São Paulo: Companhia das Letras, 2004, p. 139. 
Nietzsche o caráter fundamental do mundo não é a igualdade, o ser, mas as divergências e as contradições: o devir. No processo de sensibilização do prazer e da dor surge a igualação daquilo que originariamente não é igual. As afeições travam contato com a realidade do mundo e são mais originárias que as igualações das representações. "Todo pensar, julgar, perceber, enquanto comparação, tem como pressuposto o ato de 'pôr-em-igualdade' (Gleich-setzen), e antes ainda o ato de 'fazer-igual"'14. A afetividade configura as crenças do conhecimento e põe-se a par das contradições reais do devir, mediando uma igualação conceitual das contradições aparentes ${ }^{15}$. A contradição aparente consiste tipicamente em uma contradição lógica, baseada no princípio de não-contradição, concebido por Parmênides e desenvolvido por Aristóteles ${ }^{16}$. As contradições lógicas não são reais, i.é, não carregam em si o caráter de contradição da realidade, estão baseadas na gramática, em palavras, em conceitos. O arrazoado lógico somente se faz possível quando já se apresentou um nome, uma palavra, quando já se deu uma direção de posicionamento (Hinstellung) ao processo, quando já se vislumbrou "linhas no horizonte" 17 .

A igualação é necessária, sob determinadas perspectivas, para a "conservação da vida", a "vontade de poder" da vida ordena e manda que se siga o semelhante e evite o desigual, para efetivação de determinadas configurações de poder. A crítica de Nietzsche não se dirige exclusivamente ao processo humano de conceituação da realidade não-igual, ele sabe que esta igualação é um recurso necessário da vida. Nietzsche critica, em verdade, o absolutismo e o esquecimento desta "falsificação originária". Quando a

14 NIETZSCHE, F. Kritische Studienausgabe. Berlim/Nova York: De Gruyter, 1999, vol 12, p. 209.

15 O estudioso da obra de Nietzsche, Wolfgang Müller-Lauter, criou a distinção entre contradições reais e aparentes na filosofia de Nietzsche. As contradições lógicas não são reais, i. é, não carregam em si o caráter de contradição da realidade, porque estão baseadas na gramática, em palavras, em conceitos e, como conceitos, "tornam igual o não-igual". Cf. MÜLLER-LAUTER, Wolfgang. Nietzsche: his philosophy of contradictions and the contradictions of his philosophy. Urbana/Chicago: University of Illinois Press, 1999, p. 23-40. 16 "É impossível que a mesma coisa, ao mesmo tempo, pertença e não pertença a uma mesma coisa, segundo o mesmo aspecto". ARISTOTELES. Metafísica. Trad. Giovanni Reale. São Paulo: Loyola, 2002, p. 145, (1005 b 1921). 
contradição aparente predomina sobre a real contradição, as palavras ("as linhas do horizonte") passam a ser tomadas como pontos firmes e imóveis. Por isto, para compreendermos o conceito de igualdade na convivência humana precisamos suspender a eficácia da lógica, precisamos aprender a não tomar as palavras e os conceitos como "sinônimos" de realidade. A experiência afetiva (impulsos, paixões e afetos) é muito mais originária do que as palavras e os conceitos. Não recuperamos o sentido do conceito de igualdade, p. ex., nos reportando a outros e outros conceitos, fugindo da relação direta com o devir da realidade. Na experiência singular da sensibilidade ganhamos, segundo Nietzsche, um acesso imediato ao "sentido" da realidade enunciada. Feitas estas ressalvas, surge a questão: será que a igualação é apenas um recurso de sobrevivência do homem, mas se for isto, que tipo de humanidade queremos que sobreviva? A função exclusiva e única da igualação nominal consiste em ser "sinal" dos perigos do devir? Qual a diferença da comunicação humana para os gritos de alerta dos demais animais?

\section{A comunicação do sentimento de justiça}

Nietzsche nos desafia a abandonarmos o flatus vocis do círculo vicioso das palavras e conceitos, nos lança de volta à experiência concreta do mundo cheio de paixões e desejos: "quem não acredita em si mesmo mente sempre". Ter vergonha de comprometer-se e engajar-se na corporalidade de uma situação concreta significa caluniar a origem de toda igualdade e todo conhecimento ${ }^{18}$. O juiz que se acomoda a ler papéis, sem ouvir e dialogar com as partes, não acredita em si mesmo, tem medo de seus próprios sentimentos: desumaniza-se, torna-se uma máquina de sentenças... Neste sentido, Nietzsche foi um crítico ferrenho da erudição estéril e do funcionalismo burocrata na Alemanha do séc. XIX. Para "voltarmos ao fenômeno mesmo" da igualdade precisamos aprender a escutar a linguagem primordial da sensibilidade humana.

Aristóteles, no livro "Da Interpretação" (Perí hermenéias), nos diz que: "Os sons emitidos pela fala são símbolos das paixões da alma, [ao passo] que os caracteres

18 Cf. neste sentido os textos "Do imaculado conhecimento" e "Do pálido criminoso" em: NIETZSCHE, F. Assim falou Zaratustra. Trad. Mário da Silva, Rio de Janeiro: Bertrand Brasil, 1989, p. 134 e 54. 
escritos [formando palavras] são os símbolos dos sons emitidos pela fala." 19

Nossa fala (lógos) simboliza (semaínein) as paixões da alma (pathémata thês psikhés) ${ }^{20}$. Estas paixões são nossa forma original de sentir o mundo. Quando falamos revelamos quais são os nossos sentimentos em relação a alguém ou a alguma coisa, ainda mesmo quando tentamos esconder ou disfarçar. A linguagem é a forma tipicamente humana de mostrar e revelar o mundo. A simbologia da fala contém a totalidade das nossas relações com o mundo. Diferente dos gritos e gemidos dos demais animais, a nossa fala não se restringe a simbolizar recursos de sobrevivência biológica e "animal". A fala humana, segundo Aristóteles, não se prende exclusivamente a simbolizar os perigos ou as vantagens para a "conservação da espécie". Ou melhor, a fala humana já está sempre marcada pela definição do que seja conveniente ao homem. Ao falarmos estamos nos dizendo o que convém e o que não convém ao "homem", i.é, estamos preservando o que entendemos como verdadeira espécie humana.

"A característica específica do homem em comparação com os outros animais é que somente ele tem o sentimento do bem e do mal, do justo e do injusto e de outras qualidades morais, e é a comunidade de seres com tal sentimento que constitui a família e a cidade."’1

O "pano que rende manga" em nossas conversas é sempre o "sentimento de justiça", ou seja, falemos bem ou falemos mal disto ou daquilo, deste ou daquele outro, estamos sempre às voltas com nosso "sentimento de justiça". Nosso sentimento (aísthesis) de justiça vem à tona e se revela à medida que falamos. O que constitui uma comunidade, segundo Aristóteles, é o "sentimento de justiça", ele sempre "vai junto" (sym-ballei) de nossa linguagem. Mas, o que é esta "justiça" para Aristóteles?

19 ARISTÓTELES. Da Interpretação. Trad. Edson Bini, Bauru: EDIPRO, 2005 , p. 81 .

20 Novas reflexões sobre a doutrina da "sensibilidade" e da "estética" em Aristóteles têm destacado recentemente alguns aspectos diferentes. Cf. WELSCH, Wolfgang. Aisthesis: Grundzüge und Perspektiven des Aristotelischen Sinneslehre. Stuttgart: Klett-Cotta, 1987. 
No livro V da "Ética a Nicômacos", encontra-se o famoso tratado de Aristóteles sobre a justiça, onde ele apresenta a distinções de justiça (distributiva e comutativa), com a função corretiva desempenhada pela equidade (epieikéia). No entanto, poucos leitores desta obra se dão conta que estas distinções de justiça decorrem da exposição sobre o significado de justo (díkaios) como "igual" (ísos). Pois estas distinções não se referem ao significado de justo legal, aquele que segue a lei, mas àquele que é ísos em seus atos. "O justo, então é aquilo que é conforme a lei e correto (ísos), e o injusto (adikós) é o ilegal e iníquo"22. O significado de justiça conforme a lei (vómimon) é fácil de entender e óbvio, segundo Aristóteles, "basta obedecer e praticar os atos prescritos pela lei". O interessante é perceber que o problema da justiça encontra-se justamente na determinação do ísos, do igual. O que nos leva a crer que a compreensão da "isonomia" é decisiva para a compreensão das espécies da justiça aristotélica. Mas, isto já seria tema para outra reflexão.

Retomando nossa reflexão, podemos dizer, com base nestas considerações, que o sentimento de justiça, que se anuncia e denuncia na linguagem, corresponde no grego de Aristóteles, ao "sentimento de isonomia". Sentir a justiça então significa sentir a igualdade constitutiva do homem. Ocorre que este sentimento não é passível de novas "simbologias" de falas e palavras...- precisa ser experimentado diretamente na relação e na convivência humana. Lembrando uma outra consideração de Nietzsche: "Não basta empregar as mesmas palavras para se fazer entender: a mesma palavra empregada deve também estar referida ao mesmo gênero de vivências íntimas, deve-se, enfim, ter uma experiência em comum com o outro." ${ }^{23}$

O que constitui a humanidade do homem não é originariamente a sua capacidade de raciocínio lógico e conceitual, esta decorre a posteriori de suas afeições e sentimentos em relação ao mundo, aos outros e a si mesmo. Do sentimento de isonomia decorrem todos os discursos que promovem o bem e o mal em comunidade. Somente porque experimentamos sensivelmente o outro como alguém "igual" a nós mesmos que somos capazes de viver em comunidade, fundar cidades, civilização e cultura. A experiência de $22 \quad$ ARISTOTELES. Ética a Nicômacos. Trad. Mario Gama Kury, Brasilia: UNB, 1985, p. 92. Aristóteles usa a palavra "isos" (igual) para determinar o segundo sentido de justo. Em grego: Tó mèn díkaion ára tò vómimon kaì tò íson, tò d'ádikon to parávomon kaì tò ávison.

23 NIETZSCHE, F. Além do Bem e do Mal. Trad. Heloisa da g. Burati, São Paulo: Rideel, 2005, p. 228, (§ 268). 
humanidade está diretamente relacionada com a nossa capacidade de sentir igualdades...

João Batista Herkenhoff estava correto (ísos) quando viu uma semelhança entre o juiz e o poeta, porque o princípio da isonomia aproxima os dois. A isonomia convoca o juiz a sentir e experimentar, para além das palavras e dos conceitos jurídicos, a igualdade que funda a justiça na comunidade humana. Tal como o poeta, que está antenado com sua delicada sensibilidade, para revelar nas palavras os sentimentos da alma humana, o juiz está antenado para, partindo das palavras, acolher e retornar ao sentimento de igualdade que constitui a con-vivência humana. Encontrando a igualdade para as partes no caso concreto, o juiz não só encontra também a justiça, mas a própria humanidade de seus iguais. Somente assim uma "sentença" ganha e faz "sentido".

O juiz então restabelece a igualdade (epanísoi)... Quando o todo houver sido afinal dividido igualmente, então as partes litigantes dirão que têm aquilo que lhes pertence - isto é, quando elas houverem obtido o que é igual (tò íson). ${ }^{24}$

4. Referências Bibliográficas

ARISTÓTELES. Da Interpretação. Trad. Edson Bini, Bauru: EDIPRO, 2005. . A Política. Trad. Mario Gama Kury, Brasilia: UNB, 1997. . Ética a Nicômacos. Trad. Mario Gama Kury, Brasilia: UNB, 1985.

HERHENHOFF, João Batista. A formação dos operadores jurídicos no Brasil. In:

ARRUDA SAMPAIO, Plínio (et alii orgs.). Ética, Justiça e Direito. Reflexões sobre a reforma do judiciário. Petrópolis: Vozes, 1997.

MORAES, Alexandre de. Direito Constitucional. São Paulo: Atlas S.A., 2003.

NADER, Paulo. Introdução ao estudo do Direito. Rio de Janeiro: Forense, 2001. 
NIETZSCHE, F. Humano, Demasiado Humano. Trad. Paulo César de Souza, São Paulo: Companhia das Letras, 2004.

- A gaia Ciência. Trad. Paulo César de Souza, São Paulo:

Companhia das

Letras, 2004.

. Kritische Studienausgabe. Berlim/Nova York: De Gruyter, 1999. . Além do Bem e do Mal. Trad. Heloisa da g. Burati, São Paulo:

Rideel, 2005.

SANTO AGOSTINHO. Confissões. Petrópolis: Vozes, 1988.

SILVA, José Afonso da. Curso de Direito Constitucional positivo. São Paulo:

Malheiros Editores, 2002. 